\title{
BANDAS DE MÚSICA COMO ESPAÇOS DE ENSINO MUSICAL
}

\author{
Fernando Vieira da $\mathrm{Cruz}^{1}$
}

\begin{abstract}
Resumo
O tema abordado é a prática do ensino musical no ambiente das bandas de música brasileiras. Apresentamos uma discussão acerca das possibilidades do ensino nas bandas frente ao contexto dos espaços onde, tradicionalmente, a educação musical é discutida no âmbito acadêmico brasileiro, os conservatórios (incluindo escolas especializadas) e as escolas da rede básica de educação. Para realizar essa discussão, tomamos como base teórica a concepção de música enquanto forma de linguagem discursiva. Essa teoria advém da filosofia da linguagem e confere maior carga de significação musical às situações reais de vivência da música de modo socialmente contextualizado. $\mathrm{O}$ aporte teórico é fundamental, sobretudo, para pensarmos a concepção de ensino de música nas bandas. Logo, o objetivo deste artigo é apresentar a banda enquanto um espaço viável para ampliação das possibilidades de acesso à Educação Musical no Brasil, isso, posto frente às problemáticas enfrentadas tantos no ensino praticado em conservatórios quanto na Educação Básica. Assim, foi possível apontar que existem múltiplas potencialidades para se pensar a banda de música enquanto espaço alternativo de educação musical.
\end{abstract}

Palavras-chave: Educação Musical. Banda de Música. Espaços de Ensino. Música como Linguagem.

\section{WIND BANDS AS TEACHING SPACES}

\begin{abstract}
The theme discussed is the practice of teaching music in the environment of Brazilian wind bands. We present a discussion about the possibilities of teaching in bands in the context of spaces where, traditionally, music education is discussed in the Brazilian academic context, conservatories (including specialized schools) and schools in the basic education network. To carry out this discussion, we take as a theoretical basis the conception of music as a form of discursive language. This theory comes from the philosophy of language and gives a greater load of musical meaning to real situations in which music is experienced in a socially contextualized way. The theoretical contribution is fundamental, above all, for us to think about the concept of teaching music in bands. Therefore, the objective of this article is to present the band as a viable space to expand the possibilities of access to Music Education in Brazil, in view of the problems faced in both teaching practiced in conservatories and in Basic Education. Thus, it was possible to point out that there are multiple potentials to think of the music band as an alternative space for musical education.
\end{abstract}

Keywords: Music Education. Wind Band. Teaching Spaces. Music as Language.

\footnotetext{
${ }^{1}$ Mestre e doutorando em música pela Unicamp - Universidade Estadual de Campinas. Pesquisador associado ao Centro Latino-Americano de Estudos Sobre Cultura. Supervisor Educacional no Projeto Guri. ORCID <https://orcid.org/0000-0002-6985-1095>. E-mail: fvccruz@hotmail.com
} 


\section{INTRODUÇÃO}

A Educação Musical brasileira vem sendo discutida, recorrentemente, atrelada a dois contextos principais de realização: o primeiro é o das escolas da rede básica de ensino e o segundo é o contexto das escolas especializadas, conservatórios e cursos de nível superior de bacharelado e licenciatura (PENNA, 1999; SCHROEDER, 2012). Além disso, um outro contexto tem ganhado espaço nas discussões e pesquisas acadêmicas, são os projetos sociais de musicalização e formação de bandas, orquestras e outros grupos musicais na maioria das vezes de cunho pedagógico. As escolas da rede básica de ensino estão presentes em larga abrangência do território brasileiro. Isso possibilita, em teoria, ampla oferta da educação musical. Porém, a questão da educação musical na Educação Básica é perpassada ainda por outras questões que fazem emergir discussões sobre problemáticas amplas e complexas. A autora Maura Penna (2004a e 2004b) vêm discutindo várias dessas questões e trazendo apontamentos sobre a própria inserção da música enquanto área do conhecimento e sua subjacência/submissão ao ensino de Artes como área mais ampla. A autora aponta que, historicamente, não houve proibição ou extração da música dos currículos, porém sua presença ficou limitada mais a possibilidades/potenciais do que a propostas efetivas durante muitos anos. Isso vem ocorrendo, sobretudo por uma indefinição metodológica de Educação Musical e pela falta de um projeto de formação de professores para atuarem na realidade posta nas escolas regulares (PENNA, 2013). Além disso, a prática do ensino de música (e artes em geral) que prevaleceu por muitas décadas na Educação Básica, segundo a autora, esteve atrelada ao ensino polivalente, caminhou numa direção de esvaziamento dos conteúdos clássicos de cada linguagem artística e ficou propensa a concepções artísticas chamadas de vanguarda, que se mantêm distantes do dia a dia dos estudantes como também apontam (PENNA, 1999; SCHROEDER, 2012).

Já no contexto das escolas especializadas, conservatórios e cursos universitários ${ }^{2}$, destaca-se que, de modo geral, a prática de ensino se mostra propenso ao ensino tradicional/conservatorial em muitos momentos. O ensino tradicional é focado, principalmente no desenvolvimento das habilidades técnicas instrumentais para a formação de músicos instrumentistas através de aulas individuais. Além disso, é uma prática pautada numa concepção musical eurocêntrica (PENNA, 2008; SCHROEDER, 2005). Muitos desses espaços dedicados ao ensino tradicional, geralmente tomam músicos performers sem formação pedagógica como

\footnotetext{
${ }^{2}$ Passaremos a utilizar apenas o termo escolas especializadas para nos referirmos aos três espaços, incluindo os conservatórios e cursos universitários. Isso, principalmente em função das características metodológicas compartilhadas.
} 
professores (SCHROEDER; SCHROEDER, 2011). E ainda é preciso considerar que essas opções de aprendizado musical estão mais presentes nos grandes centros, o que dificulta a possibilidade de serem pensados como opção viável para a oferta da Educação Musical de modo abrangente e acessível. Assim, os desafios pendentes são o de promover a Educação Musical de modo abrangente em todo o amplo território brasileiro, além da adoção de uma prática de ensino acessível, contextualizada das diferentes realidades culturais regionais em todo o país, portanto mais próxima e significativa do contexto de vida dos estudantes.

Nesse sentido, apresentamos as bandas de música como potenciais espaços para superar os dois desafios postos. Presentes em amplo território nacional, as bandas de música também têm suas atividades realizadas no ambiente escolar como projetos de contra turno e vêm sendo apontadas como opção viável para o ensino de música na Educação Básica como faz Barbosa (1996). Obviamente, as bandas também apresentam suas problemáticas quanto a concepção de ensino que adotam. Não reconhecidas como espaços formais de ensino de música, geralmente se dedicam a formação de novos componentes para os grupos e sustentam forte herança do ensino tradicional/conservatorial. Porém, diversos estudos apontam para uma movimentação em direção a superação dessa herança. Cruvinel (2017), apresenta um panorama do ensino coletivo de instrumentos musicais incluindo algumas iniciativas em bandas já no início da segunda metade do século XX. Barbosa $(1994,1996)$ defende a proximidade do ensino coletivo em bandas com o cotidiano musical dos aprendizes como forma de tornar a aprendizagem mais significativa ${ }^{3}$.

Neste texto, abordaremos os desafios metodológicos e da presença em amplo território nacional que são enfrentados pela Educação Musical apresentando as bandas de música como potencial espaço de superação deles. Mais especificamente, abordaremos esses dois temas no contexto de atividade e ensino musical nas bandas de música. A discussão que apresentamos aqui trata-se de um recorte da nossa pesquisa de mestrado sobre o ensino em bandas de música (CRUZ, 2019). A pesquisa analisou a Corporação Musical Nossa Senhora do Carmo da cidade de Itu/SP, uma banda comunitária histórica de cunho pedagógico. A banda foi fundada em 1952 por Antônio Rodrigues da Silveira, o maestro Toniquinho por demanda da Congregação Mariana da Igreja Católica de Itu/SP. O objetivo da pesquisa era compreender as forças motrizes que potencializaram a continuação de suas atividades e o desenvolvimento musical do

\footnotetext{
${ }^{3}$ É importante ressaltar que essa defesa esteve presente na tese de doutorado do autor que foi defendida em 1994 e se estende na publicação do Método Da Capo para bandas, que é baseado em melodias das canções populares infantis brasileiras. Apesar de o método ter sido publicado apenas em 2004, ele foi elaborado durante a pesquisa de doutorado do autor e foi publicada como anexo da tese defendida.
} 
grupo e de seus componentes. O trabalho de campo incluiu um semestre de observação do cotidiano da banda entre aulas, ensaios, momentos de socialização e concertos. Durante a análise dos dados incluímos amplos diálogos com a bibliografia que trata do tema com estudos sobre bandas atuantes em diferentes momentos históricos e regiões do Brasil. A partir disso, foi possível perceber que as potencialidades presentes nas bandas de música são recorrentes e revelam um processo histórico de desenvolvimento identitário dessa manifestação cultural. Ou seja, as potencialidades que promover a continuação das atividades e desenvolvimento musical das bandas se mostraram também persuasivas quanto a sua conformação identitária. Desse modo, traremos para o presente texto alguns dos episódios analisados na dissertação que, ao nosso ver, podem fazer frente aos desafios da Educação Musical que apontamos anteriormente. Isso, tanto pela capacidade das bandas em se adaptarem a diferentes contextos regionais quanto pela sua ampla presença em território nacional.

O aporte teórico que adotamos advém da filosofia da linguagem, mais especificamente do filósofo russo Mikhail Bakhtin ${ }^{4}$ e da leitura de sua teoria na música feita pela educadora Silvia Cordeiro Nassif Schroeder (2005). Os principais conceitos que utilizaremos neste texto são: dialogia, discurso e refração. Os conceitos da teoria de Volóchinov/Bakhtin (2017) são basilares para o entendimento da concepção de música enquanto forma de linguagem, suas formas de significação e aprendizado apresentada por Schroeder (2005). De modo conciso, a concepção de música como linguagem que adotamos entende que a música é uma forma de linguagem socialmente significada. Ou seja, é nas situações reais de vivência musical e dentro de um contexto social comum aos participantes de tal experiência que reside a maior carga de significação da música. A música é entendida como uma linguagem discursiva. Toda elaboração musical está, concomitantemente, respondendo e sendo respondida por um outro discurso. Cabe ainda que as formas de dialogar musicalmente estão postas na concepção de dialogia de Volóchinov/Bakhtin (2017). Nela, dialogar significa responder em concordância ou não, imediatamente ou após longo tempo, com uma elaboração da mesma natureza ou outra. Assim, dialogar musicalmente é mais do que tocar ou cantar, é responder ao evento musical de qualquer modo, seja se envolvendo na experiência e elaborando seus discursos imediatamente ou compondo uma música em outro momento, dançando, falando, reagindo emocionalmente

\footnotetext{
${ }^{4}$ Mikhail Bakhtin foi um filósofo que liderou um grupo de pensadores de diferentes áreas que se reuniam sistematicamente durante as décadas de 1920 e 1930. O grupo, que ficou conhecido como Círculo de Bakhtin, dedicou-se ao estudo das criações simbólicas humanas. Bakhtin se dedicou mais especificamente ao estudo da literatura, porém seu pensamento é extensível às artes e à música como apresentaremos ao longo deste artigo. Há muitas controvérsias sobre a autoria de vários textos produzidos pelos participantes do grupo. Assim, o principal texto utilizado, "Marxismo e Filosofia da Linguagem", será citado com referência aos dois autores aos quais o mesmo vem sendo atribuído: Mikhail Bakhtin e Valentin Volóchinov.
} 
ou simplesmente fruindo daquela experiência. A experiência de dialogar é, portanto sempre transformadora para quem discursa, quem responde e dos próprios discursos postos em diálogo. Todo discurso ocorre numa realidade dinâmica, refratária.

Dessa forma, os conceitos brevemente apresentados nos ajudam a lançar luz em nosso próprio campo de investigação, as bandas de música, sua construção identitária histórica, suas formas de significar e discursar a música, e as possibilidades do ensino musical no seu contexto como apresentamos anteriormente em Cruz ( 2019 e 2020) e Cruz e Cruz (2018). Ou seja, é a partir dessa concepção que entendemos que há potencialidades nos ambientes das bandas de música para a promoção de uma Educação Musical que faça frente às problemáticas apresentadas no contexto do ensino de música no Brasil. O texto segue com uma contextualização do desenvolvimento histórico das bandas em território brasileiro e da forma como esses grupos vêm reconfigurando suas identidades e estratégias de ensino de música. Essa primeira parte se vale, predominantemente, do diálogo com a bibliografia explorada durante a pesquisa da qual o artigo se recorta. Em seguida, o texto apresenta uma discussão de algumas das potencialidades presentes no desenvolvimento histórico das bandas que reverberam em suas práticas pedagógicas. Por fim, apresentamos nossas considerações sobre as características da formação dos grupos e de suas práticas pedagógicas como potenciais caminhos para desvelar as problemáticas sobre a Educação Musical apresentadas anteriormente.

\section{DESENVOLVIMENTO E ENSINO MUSICAL NAS BANDAS}

Diferentes estudos apontam para uma construção identitária das bandas de música dada na pluralidade de costumes, valores, repertórios e culturas. Pudemos averiguar essa presente em estudos sobre bandas de diferentes regiões do Brasil e em diferentes momentos históricos. Com registro de sua presença em território brasileiro desde 1549 (PEREIRA, 1999), o longo percurso das bandas vem imprimindo em sua identidade diferentes vetores que resultam numa multiplicidade de características, tipos de bandas, estilos de repertórios e práticas musicais. De modo sucinto, esses vetores que perpassam a identidade das bandas estão postos em sua interação com diferentes segmentos da sociedade como o campo religioso (DUPRAT, 1968, 2009), entretenimento e festas populares (LANGE, 1998; SCHWARCZ, 1998), com o militarismo e suas relações simbólicas de poder (BINDER, 2006; REILY, 2009), transformações tecnológicas (SOUZA, 2009) e também com o campo educacional (BARBOSA, 1994; BENEDITO, 2011; MOREIRA, 2007). Além disso, o forte senso de 
pertencimento às comunidades nas quais as bandas residem, reafirmam a capacidade de se adaptar e refratar aos contextos culturais locais onde atuam (CRUZ, 2020).

No mesmo sentido de uma construção identitária dada na pluralidade de condições de atuação, alguns estudos apontam o desenvolvimento musical das bandas de música em função do contato com diferentes técnicas e estilos musicais como é o caso de Pereira (1999) e Duprat (2009). Assim, ao interagir com diferentes campos de atividades a banda e seus componentes passaram a transitar por diferentes gêneros musicais. Essa atuação diversa persuadiu a própria identificação dos discursos musicais dos grupos vinculada a constantes transformações dos mesmos. Aqui reside substancial relevância de nossas observações a partir da diversidade de realidades cotidianas presentes historicamente nos ambientes das bandas. Ou seja, a banda se constrói em ambiente aberto e poroso a diferentes realidades culturais e uma diversificada gama de discursos musicais. Partindo tanto da bibliografia quanto das observações empíricas, a construção identitária das bandas e seu desenvolvimento musical sempre se mostraram perpassados pelo repertório durante essas interações. Os grupos são compostos por pessoas oriundas de diferentes segmentos da sociedade, com diferentes costumes, valores e modos de significar a música. Logo, as interações que ocorrem de modo mais intimista ao ambiente das bandas colocam em contato diferentes gerações, culturas, concepções e preferências musicais. Nessas interações, pudemos observar uma variedade de experiências de significações musicais ocorrerem de modo descontraído, fluido e não intencional. Observamos ainda que, além de promover significativas experiências de aprendizado musical, tais dinâmicas persuadiram ainda os momentos intencionais de ensino de música, na formação do repertório e na identificação do grupo potencializando o aprendizado de maneira democrática, ampla e contextualizada da realidade de seus componentes.

Além de já se fazer presente no cotidiano da sociedade brasileira com uma prática aberta de ensino de música, as bandas vêm ganhando espaço nas discussões acadêmicas como lócus do pensar diferentes maneiras do ensino de música. Isso, tanto nos espaços próprios de atuação das bandas como possibilidade para efetivar a presença da música na Educação Básica como discute Barbosa (1996) quanto como projetos de extensão universitária abordado por Moreira (2020). Portanto, para apontar a banda como possibilidade de superar os desafios apresentados para a Educação Musical brasileira no início deste texto, passamos a um breve contexto de como o ensino de música vem sendo discutido, academicamente, nas bandas de música.

Barbosa $(1996,2009)$ faz uma retomada histórica do desenvolvimento do ensino de música nas bandas e apresenta duas grandes tendências. De modo geral, existe uma corrente de 
prática de ensino tradicional de música, muito próxima do ensino tradicional que é recorrente em conservatórios, escolas especializadas de ensino de instrumentos e cursos universitários. Uma segunda tendência passa a ganhar espaço a partir do fomento do repertório e dos métodos coletivos estadunidenses no Brasil. Assim, o ensino tradicional vem cedendo espaço para o ensino coletivo desde o início do Século XX. Vale destacar que esses métodos coletivos têm grande proximidade com as metodologias que pensam a educação musical inserida num projeto de formação integral do sujeito. Ou seja, buscam pensar para além da formação de músicos instrumentistas, objetivo mais comum até então no modelo de ensino predominante nas bandas. Podemos citar o próprio Método Da Capo de Joel Barbosa (1994), elaborado a partir da adaptação metodológica de métodos estadunidenses com o uso de melodias brasileiras. Em sua pesquisa, o autor se apoia em diferentes autores como Zoltán Kodály e Carl Orff para apontar os benefícios de práticas mais comuns nas propostas de musicalização quando fomentadas no ensino em bandas como: cantar, tocar de ouvido, criar e improvisar, e tocar por imitação.

Consideramos que o ensino de música nas bandas se caracteriza, igualmente a construção identitária das bandas brasileiras, por sua dinâmica, instabilidade e contínuo processo de transformação. É nessa condição transitória que enxergamos as potencialidades para as bandas de música ofertarem uma Educação Musical ampla e capaz de ser contextualizada da ampla gama de diversidade cultural brasileira. Porém, essa amplitude de possibilidades também acusa a existência de uma prática híbrida de procedimentos pedagógicos e metodológicos. Ou seja, mesmo imersos no ensino pelos métodos coletivos com fortes traços de proximidade e fundamentação metodológica ligadas aos Métodos Ativos em Educação Musical (FONTERRADA, 2005), como é o caso do método Da Capo, não há abandono de práticas ligadas ao ensino tradicional como o uso de partituras e a necessidade da leitura para participação (com execução instrumental) nos grupos. Dessa forma, podemos afirmar que as bandas de música brasileiras carregam características de aproximação com os dois contextos postos em contraponto no início deste texto, àqueles ligados às práticas mais próprias da rede básica de ensino e dos conservatórios e escolas especializadas.

Portanto, entendemos que seja preciso um certo rigor epistemológico e metodológico para pensar o ensino de música nas bandas sem cair no afastamento da realidade cultural dos estudantes. Assim, seguimos apresentando como pensamos a própria historicidade e concreticidade da banda de música como lócus do conhecimento para o ensino nela intencionado. Tornamos então, a diversidade de vetores presentes no processo de construção identitária histórica das bandas como fator predominante do desenvolvimento histórico e 
musical dos grupos e, portanto, potencialidades concretas e históricas para se pensar o ensino de música nas bandas. Algumas dessas potencialidades são: a coletividade, o senso de pertencimento, a diversidade de repertório e a constante adaptação das bandas em seus contextos de atuação.

\section{AS POTENCIALIDADES NO ENSINO EM BANDAS}

Como dito, as bandas de música brasileiras vêm se construindo por um processo histórico de adaptação e reposicionamento ante a sociedade. A banda de música que estudamos em recente pesquisa de mestrado (CRUZ, 2019) se mostrou profusa numa realidade plural com atuação ligada a execução de repertório de grande variedade de gêneros musicais. Sobretudo, ressaltamos que parte do repertório era nutrido inclusive pela interação com a comunidade, com novas tecnologias de comunicação, sugestões e preferências musicais de seus alunos etc. Já o ensino intencional de música partia de bases tradicionalistas, mas se valia de métodos de ensino coletivo, o que acabava por abrir espaço para diferentes leituras e práticas pedagógicas baseadas nas condições locais de atuação. Essa duplicidade se deu, provavelmente, em função de que mesmo sendo a formação do maestro de origem conservatorial, ele era o único contratado para ensinar, ensaiar, reger, fazer arranjos e liderar o desenvolvimento da concepção artística do grupo. Daí, o ensino em grupo através de métodos coletivos parecia fazer mais sentido do que replicar as práticas do ensino conservatorial através de aulas individuais. É a partir dessa realidade plural de repertórios e práticas de ensino que vimos emergir as realidades dos momentos de descontração e do cotidiano como potencialidades pedagógicas no ambiente da banda de música.

\footnotetext{
Enquanto alguns músicos aguardavam a chegada de outros, um aluno de trompete tocava repetidamente um trecho do seriado Game of Thrones. O maestro da banda, percebendo, chamou-o para conversar e disse que tinha um arranjo dessa música para a banda tocar, e que em duas semanas começariam a ensaiar esse arranjo (CRUZ, 2019, p. 57 e 58).
}

Vemos uma clara movimentação de uma experiência musical lúdica em momentos de descontração sendo levada para os momentos de atividades intencionais e participando da elaboração do discurso da banda como um grupo, coletivo. Ou seja, um momento de fazer musical descompromissado persuadiu a própria formação do repertório da banda. Apesar de o ambiente da banda ser profuso em procedimentos de ensino tradicionais muito próximos daqueles praticados nas escolas especializadas e historicamente atrelado ao repertório de 
tradição ocidental (PEREIRA, 1999; BARBOSA, 1996) a atitude do maestro é um indicativo de abertura desse espaço para as múltiplas possibilidades discursivas musicais. Esse tipo de interação é, para nós, um dos caminhos pelos quais percebemos o repertório da banda de música ser construído por uma grande diversidade de gêneros musicais. Por fim, destacamos dessa situação a abertura para um processo de ensino musical contextualizado da realidade musical dos alunos, portanto significativo dentro de um contexto social que integra locutor e interlocutor, alinhado à concepção de música como linguagem discursiva que adotamos. Isso revela ainda uma abertura para se pensar a banda frente ao desafio da diversidade cultural brasileira. Além disso, a entrada de diferentes práticas e culturas no ambiente das bandas persuadiram mais do que o repertório e mostraram transformações na própria maneira de interagir dos seus componentes. Ao mesmo tempo em que as bandas de música se fazem presentes em amplo território, elas constroem seus próprios paradigmas através de cada realidade local, sua cultura, seu repertório, costumes e valores.

Trazemos outra situação que ocorreu fora dos momentos de aulas, em que os alunos interagiram com brincadeiras musicais, tocando trechos do repertório, conversando sobre os arranjos, experimentando diferentes instrumentos etc.

Todos chegaram para o ensaio ainda nos minutos finais da aula coletiva, e começaram a conversar animados, muitos tocavam seus instrumentos (trechos de músicas do repertório já visto em ensaio), por vezes os alunos trocavam de instrumentos e por vezes queriam "brincar" um pouco tocando na bateria. Alguns comentários puderam ser ouvidos como "... nossa, como é diferente tocar essa música no sax..." (CRUZ, 2019, p. 105).

Essas experiências e brincadeiras de experimento de diferentes instrumentos eram mediadas pelos próprios alunos. Porém, essa mediação não nos pareceu limitar-se a tarefa de execução instrumental, enquanto os alunos experimentavam novos instrumentos, faziam comentários de que a música que estavam tentando tocar parecia diferente tocada naquele instrumento. $\mathrm{O}$ fato é que esses alunos já tocavam aquelas músicas nos instrumentos que já conheciam. Assim, a perspectiva de percepção e significação da música que tentavam tocar eram perpassados pelas explicações de outros alunos e também pela sensação experimentada em diferentes instrumentos. Esses momentos, por si só, poderiam ser tomados como potencializadores do aprendizado ao ofertar aos alunos experiências diversificadas e diferentes perspectivas de percepções da música em relação às atividades intencionais de aulas e ensaios. A significação musical contou com diferentes discursos e percepções compartilhadas dentro de um mesmo contexto social. Da mesma forma que Volóchinov/Bakhtin (2017) entendem a significação da linguagem através dos diálogos em contextos socialmente compartilhados e

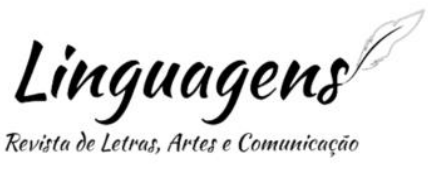


Schroeder (2005) aponta para diversidade de possibilidades de significação da linguagem musical, no ambiente da banda os discursos musicais se mostraram construídos e compreendidos através dessa trama de vozes e discursos cotidianos internos. Tal dinâmica torna-se ainda mais promissora quando se movimenta dos momentos de descontração para as aulas e ensaios onde existe a intencionalidade do ensino da música. Assim, coletividade e pluralidade cultural, de repertórios, costumes e valores compõem e transformam uma mesma realidade no ambiente das bandas.

\begin{abstract}
Neste momento, enquanto o maestro fazia algumas explicações aos alunos de percussão, os músicos de instrumentos de sopro voltaram a conversar, em alguns casos apontavam para a partitura, experimentavam tocar um pequeno trecho e voltavam a conversar e apontar para a partitura; a aluna de flauta 1 disse: -“...é assim esta parte..." e tocou o trecho novamente, a aluna de flauta 2 observou e depois tocou também perguntando se a execução estava correta, sendo aprovada pela aluna de flauta 1 (CRUZ, 2019, p. 103).
\end{abstract}

Já nos momentos de aulas e ensaios, nas situações em que o maestro dispensava atenção a algum naipe específico os outros alunos conversavam entre si, sanavam dúvidas e, consequentemente, experimentavam diferentes formas de compreensão de determinados trechos que não haviam sido "resolvidos" durante os exercícios. Nesse momento, as potencialidades subsidiando a significação musical extrapolam os momentos extraoficiais e penetram a própria atividade de aula. Ou seja, essas experiências de aprendizado musical transitaram dos momentos de descontração e vivência musical descompromissada para os momentos de aulas intencionais. Isso porque em muitos momentos foi possível observar que ao perceber essas interações, nesses pequenos intervalos, o maestro da banda não repreendia e nem tentava evitar tais situações. Foi possível ainda, averiguar que o maestro percebia que essas interações estavam colaborando com o processo de aprendizado. Destacamos que a interação entre os alunos ocorria por uma dinâmica própria, mais livre de formalidades com relação às interações dos alunos com o maestro. Assim, vemos na banda uma possibilidade de transitar o ensino musical entre momentos do cotidiano e situações formais, a brincadeira e as atividades protocolares etc. É possível pensar a banda como um espaço intermediário no qual o aprendizado musical leve em conta a subjetividade dos alunos com a interlocução do educador. Isso, fazendo frente aos desafios apontados para a Educação Musical brasileira.

Um outro exemplo de conexão entre os momentos de socialização e as aulas/ensaios ocorreu quando o maestro fez alguns comentários para explicar determinados trechos da música dando referências dos instrumentos musicais. Para exemplificar a intenção de maior intensidade e precisão rítmica de um trecho musical, o maestro pediu que todos imaginassem o trecho 
tocado por uma caixa militar. Em outros momentos o maestro chegou a tocar um ou outro instrumento para exemplificar o caráter que intencionava alcançar com a execução da banda. Fez exemplificações de um trecho que deveria soar gracioso como o timbre da flauta transversal e outro trecho melodioso como o saxofone. Ao fomentar referências de diferentes instrumentos o maestro acaba trazendo à tona as experiências vivenciadas pelos alunos durante os momentos de descontração. Sendo essa atitude do maestro intencional ou não de fazer tal conexão, o fato é que as potencialidades de aprendizado musical daquelas experiências/brincadeiras tiveram espaço aberto para se fazerem presentes durante a aula. Não podemos afirmar de fato quais foram as intenções subjetivas dos comentários do maestro, também não podemos inferir de modo direto como as explicações foram recepcionadas/compreendidas por cada componente do grupo. Portanto, com referência a situação analisada podemos afirmar apenas que essa conexão esteve potencialmente presente durante a atividade. O que nos chama a atenção aqui é exatamente a possibilidade de explorar essa conexão de relações como potencializadora do ensino de modo intencional. A estratégia utilizada pareceu cumprir seu papel de acordo com o que percebemos, pois o maestro se mostrou satisfeito com a execução da banda.

\section{CONSIDERAÇÕES FINAIS}

Por fim, a porosidade cultural das bandas de música nos pareceu cumprir relevante papel de ampliar as possibilidades de vivências e perspectivas de significação musical. Isso ficou claro no nível potencial em situações de interações musicais espontâneas em momentos de livre convivência nos intervalos de aulas. Também se mostrou presente na entrada dessa perspectiva de vivência musical em aulas e ensaios tornando uma potencialidade em atitudes pedagógicas. Ou seja, abarcar a forma como os alunos vivenciam a música em seus cotidianos nas atividades de aulas e ensaios permite ampliar a trama de discursos musicais presentes no processo de aprendizagem. Essa abertura ficou ainda mais evidente na persuasão do cotidiano musical dos alunos no próprio repertório da banda. Enfim, entendemos o ensino pelas potencialidades pedagógicas dependente de uma postura educacional imersa em alteridade e atitudes democráticas. Deve considerar os discursos musicais dos alunos abertamente, seus repertórios cotidianos, e a dinâmica de interação deles com tal repertório. Essa aceitação da pluralidade de discursos musicais se mostra como uma vertente para se pensar a viabilidade das bandas enquanto espaços de acesso à Educação Musical de modo democrático. Sobretudo, para a realidade diversa de manifestações culturais no vasto território brasileiro. 
A atuação das bandas enquanto espaço de ensino de música se destaca, mas não se restringe às pequenas cidades interioranas do Brasil como discute Pereira (1999). Frente à realidade de atuação dos conservatórios, as bandas se destacam por representarem como espaços mais abertos, sobretudo para acolher os menos afortunados e desprovidos do acesso aos instrumentos que são de alto custo (SALLES, 1985), além disso, acolher, inclusive, seus discursos, vivências e formas de significar a música. Ainda, é preciso lembrar que a maioria das práticas de ensino de música instrumentais nas escolas de rede básica se dão pela presença dos projetos extracurriculares de bandas e fanfarras. Assim, a realidade contraditória da banda de música figura, para nós, como uma possível intersecção, um ponto de equilíbrio da condição binária dos contextos das escolas da rede básica e dos conservatórios musicais. O motivo recorrente é sua realidade diversa presente em vasto território e composta num ambiente aberto a diferentes culturas. Portanto, entendemos que a banda pode ser um caminho possível de se transpor os desafios da educação musical brasileira aqui apresentados ao passo que se considere sua realidade plural presente em seu repertório, história, atuação, público, alunos e formas de interagir como potencializadores do ensino.

\section{REFERÊNCIAS}

BARBOSA, Joel Luis. An adaptation of american band instruction methods to brazilian music education, using brazilian melodies. 1994. University of Washington, 1994.

BARBOSA, Joel Luis. Considerando a Viabilidade de Inserir Musica Instrumental no Ensino de Primeiro Grau. Revista da ABEM, Salvador, v. 3, n. 3, p. 39-50, 1996.

BARBOSA, Joel Luis. Tradição e inovação em bandas de música. In: Mary Angela Biason, (Org.) Anais do I seminário de música do museu da inconfidência bandas de música no brasil 2009, Ouro Preto/MG. Anais [...]. Ouro Preto/MG: Museu da Inconfidência, 2009. p. $65-74$.

BENEDITO, Celso José Rodrigues. O mestre de filarmônica da bahia: um educador musical. 2011. Universidade Federal da Bahia, 2011. Disponível em: https://repositorio.ufba.br/ri/handle/ri/9101.

BINDER, Fernando. Bandas militares no Brasil: difusão e organização entre 1808-1889. 2006. Universidade Estadual Paulista, 2006.

CRUVINEL, Flavia Maria. Ensino Coletivo de Instrumento Musical como Educação Popular: alguns apontamentos. In: LOPES, Eduardo (org.). Tópicos De Pesquisa Para a Aprendizagem Do Instrumento Musical. Goiânia/GO: Editora Kelps, 2017. p. 234-251. Disponível em: www.kelps.com.br.

CRUZ, Fernando Vieira Da. A (Re)Construção da Banda de Música: Repertório e Ensino. 2019. Unicamp - Universidade Estadual de Campinas, BR, 2019. Disponível em: 
http://repositorio.unicamp.br/handle/REPOSIP/333950.

CRUZ, Fernando Vieira Da. Banda de Música e Identidade Cultural. In: Estudos LatinoAmericanos Sobre Música. Editora Artemis. v. 1p. 159-170. DOI:

10.37572/EdArt_149100920. Disponível em:

https://www.editoraartemis.com.br/artigo/31815/.

CRUZ, Fernando Vieira Da; CRUZ, Dayana Aparecida Marques de Oliveira. Reflexões da prática pedagógica voltada à criação musical. Reflexão e Ação, BR, v. 26, n. 2, p. 267282, 2018. DOI: 10.17058/rea.v26i2.4852. Disponível em:

https://online.unisc.br/seer/index.php/reflex/article/view/4852/pdf.

DUPRAT, Régis. Música na matriz de São Paulo Colonial. Revista de história, v. 37, n. 75, p. 85-103, 1968. DOI: https://doi.org/10.11606/issn.2316-9141.rh.1968.128465. Disponível em: http://www.revistas.usp.br/revhistoria/article/view/128465.

DUPRAT, Régis. Uma pesquisa sobre a Música Popular Brasileira do século XIX. In: (Mary Angela Biason, Org.) Anais do I seminário de música do museu da inconfidência: bandas de música no brasil. 2009, Ouro Preto/MG. Anais [...]. Ouro Preto/MG: Museu da Inconfidência, 2009. p. 32-39.

FONTERRADA, Marisa Trench de Oliveira. De Tramas e fios: um ensaio sobre a música e educação. São Paulo: Editora Unesp, 2005.

LANGE, Francisco Curt. Las bandas de música en el Brasil. Revista musical chilena, v. 51, n. 187, p. 27-36, 1998. DOI: 10.4067/s0716-27901997018700003. Disponível em: https://revistamusicalchilena.uchile.cl/index.php/RMCH/article/view/13049.

MOREIRA, Marcos dos Santos. Aspectos históricos, sociais e pedagógicos nas filarmônicas do divino e nossa senhora da conceição, do estado de sergipe. 2007. Universidade Federal da Bahia, 2007. Disponível em: https://repositorio.ufba.br/ri/handle/ri/9134.

MOREIRA, Marcos Santos. JPMB: Qualificação da performance no contexto da educação musical comunitária em cidades interioranas de Alagoas. Revista Orfeu, v. 5, n. 2, p. 118, 2020. DOI: $10.5965 / 2525530405022020 \mathrm{e} 0011$.

PENNA, Maura. Ensino de Arte: um momento em transição. Pro-Posições, v. 10, n. 3, p. 57-66, 1999.

PENNA, Maura. A dupla dimensão da política educacional e a música na escola: I: analisando a legislação e termos normativos. Revista da ABEM, v. 12, n. 10, p. 19-24, 2004. a. Disponível em:

http://www.abemeducacaomusical.com.br/revistas/revistaabem/index.php/revistaabem/article/ view/358.

PENNA, Maura. A dupla dimensão da política educacional e a música na escola: II - da legislação à prática escolar. Revista da ABEM, v. 12, n. 11, p. 7-16, 2004. b. Disponível em:

http://www.abemeducacaomusical.com.br/revistas/revistaabem/index.php/revistaabem/article/ view/342.

PENNA, Maura. Música(s) e seu ensino. Porto Alegre. v. 53

PENNA, Maura. A Lei 11.769/2008 e a Música na Educação Básica: quadro histórico, 
perspectivas e desafios. InterMeio, v. 19, n. 37, p. 53-75, 2013. Disponível em: https://periodicos.ufms.br/index.php/intm/article/view/2361.

PEREIRA, José Antônio. A Banda de Música: retratos sonoros brasileiros. 1999.

Universidade Estadual Paulista, São Paulo. Editora da Unesp, 1999.

REILY, Suzel Ana. Bandas de sopro - um diálogo transcultural. In: anais do I seminário de música do museu da inconfidência: bandas de música no brasil. 2009, Ouro Preto/MG. Anais [...]. Ouro Preto/MG: Museu da Inconfidência, 2009. p. 23-32.

SALLES, Vicente. Sociedades de Euterpe as bandas de música no Grão Pará. Edição do ed. Brasília/DF.

SCHROEDER, Silvia Cordeiro Nassif. A arte como linguagem: um olhar sobre as práticas na educação infantil. Leitura: Teoria e Prática, v. 30, n. 58, p. 77-85, 2012.

SCHROEDER, Sílvia Cordeiro Nassif. Reflexões sobre o conceito de musicalidade: em busca de novas perspectivas teóricas para a educação musical. 2005. Universidade Estadual de Campinas, 2005.

SCHROEDER, Silvia Cordeiro Nassif; SCHROEDER, Jorge Luiz. Música como discurso: uma perspectiva a partir da filosofia do círculo de Bakhtin. Música em Perspectiva, v. 4, n. 2, p. 127-153, 2011. DOI: 10.5380/mp.v4i2.27495. Disponível em: https://revistas.ufpr.br/musica/article/view/27495.

SCHWARCZ, Liliam Moritz. As Barbas do imperador, D. Pedro II: um Monarca dos Trópicos. 2. ed. São Paulo/SP: EDITORA SCHWARCZ, 1998.

SOUZA, David Pereira. As gravações históricas da Banda do Corpo de Bombeiros do Rio de Janeiro (1902-1927): valsas, polcas e dobrados. 2009. Universidade Federal do Estado do Rio de Janeiro, 2009.

VOLÓCHINOV, Valentin; BAKHTIN, Mikhail. Marxismo e filosofia da linguagem: Problemas fundamentais do método sociológico na ciência da linguagem. $1^{\circ}$ ed. São Paulo/SP: EDITORA 34, 2017. 